\title{
CD-BASED ORGANIZATION OF BUSINESS SYSTEMS
}

\author{
COVIC, D[ragan] \& COVIC, D[aniela]
}

\begin{abstract}
While seeking solutions for an increased intensity of changes in a business system environment, we should think beyond standard, logical, normal views of business system organization. Hundreds of solutions offered so far have not accommodated organizational structures to permanent and increasingly complex demands of management theory and practice. What we offer through a CD-based organizational structure of a business system is turning of a business system structure into a live organism that keeps searching new, better and more perfect solutions. A basic business unit is a source motivated to innovativeness and unlimited circulating of knowledge in real time. Atoms vs. bits balance enables a CDorganization to decompose "tiredness" and strengthen influence of basic business units in the environment. Networking and multiplying of the most diversified technological, economic and legal components results in a specific value of the CD-organization of business systems. In a CD-organization everything is temporary and it is difficult to recognize either the beginning or ending of any process, having in mind that it is elastic and never-ending sequence of creation of new items by combining and merging seemingly incompatible items.A CD-organization is not racing against time, since all processes of expansion as well as deconstruction take part in real time
\end{abstract}

Keywords: organization, business syste, knowledge core, basic business unit

\section{INTRODUCTION}

We want to free ourselves from temporal, cultural, technological, geographical and legal barriers and become attractive motivators of reproduction and networking. We are looking for an organizational model that will be recognizable for its imagination, emotion, ethics, inventiveness, freedom and knowledge as its basic values. Horizontally oriented networking of institutional technologies and values will create a new organizational world based on knowledge. In the entire thinking of a CD-organization of business system organization we started from the beginning, the most elementary basics of business system functioning, toward solutions for transformation of input and output values of any business process

\section{CD - ORGANIZATION OF BUSINESS SYSTEMS BUSINESS SYSTEM ELASTICITY}

In order to better understand values of a CDorganization of business systems, we provided an outline of the structure of this type of organization (Figure 1)

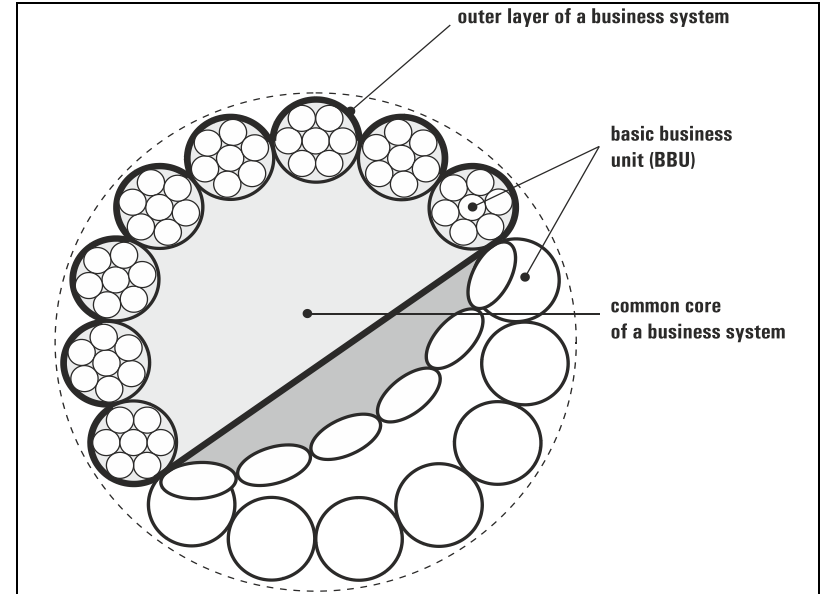

Fig. 1. CD- organization of a business system - structure

A basic business unit of a business system is autonomous up to a point of sustainability. It is left to the imagination, emotional capacity and creativity of an individual, as a basis of its infrastructure. Self-stimulated to multiply and merge - to mix atoms by means of bits. Endless integral exchange of capital with a common core is aimed at self-destruction of tired-old units and creation of new ones, within the same business unit or in a completely newly built one. Temporariness is one of the characteristics of a basic business unit; it lives, reproduces and acts in real time. Circulation of information in real time, among all basic business units, is an integral and continuous process that strengthens their elasticity under the same layer.

A basic business unit's layer is very elastic; it transforms under the influence of other basic business units and especially under the pressure and attacks from the environment. Structure of a basic business unit is similar to the structure of the outer layer of CDorganization of a business system.Legal basis for individual basic business units is motivated by a mixture of different legal standards, as a result of individual efforts within each basic business unit. They can be result of different business deals, contracts, or transformation of shares structure as a part of motivating policy of a business system. Organized individuals represent strength of basic business units, and in the form of a strong team they multiply level of usage of their own intellectual potential.

They do not allow to be treated as human resources, since in such a one-on-one game they create an organization without hierarchy. Marked temporariness of their joint action depends on:- production of newinnovative value and readiness to eliminate-deconstruct tired units in the field of marketing, technology, design, 
quality, finances or any other function or project that gathers them. Emphasis on temporariness and projected idea of self-destruction relaxes basic business units and its structures from the stress and emotional experience. Common outer layer and core of a business system are motivating enough for an individual to contribute to development of their business system while following simple rules of circulation of ideas, information, imagination and knowledge in general.

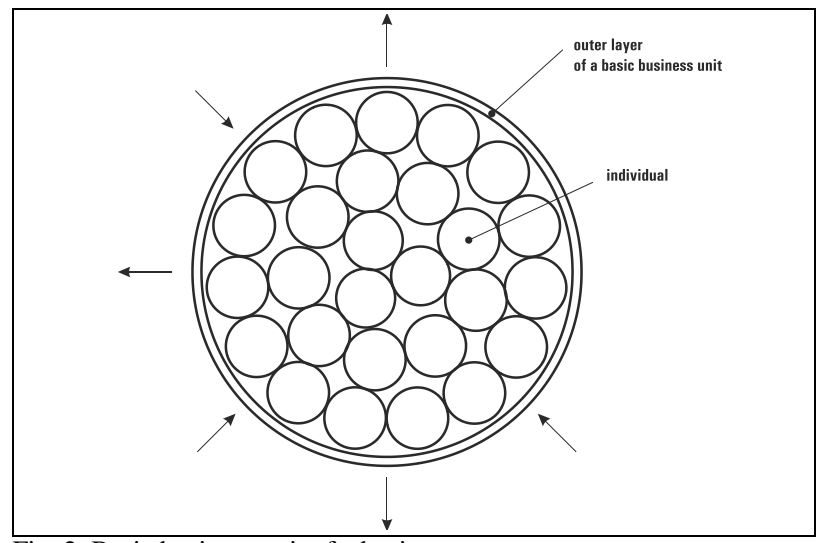

Fig. 2. Basic business unit of a business system - structure

In order to make a contribution to functioning of a basic business unit, an emphasis in knowledge exchange is moved from linear to exponential. Flow of ideas, knowledge and capital on a horizontal level between a basic business units of a business system, a process is started which does not enable determining of the beginning or ending of a CD organization of a business system. An emphasis on horizontal in a CD organization guarantees a more developed and better used present knowledge, which forces slower ones to act.

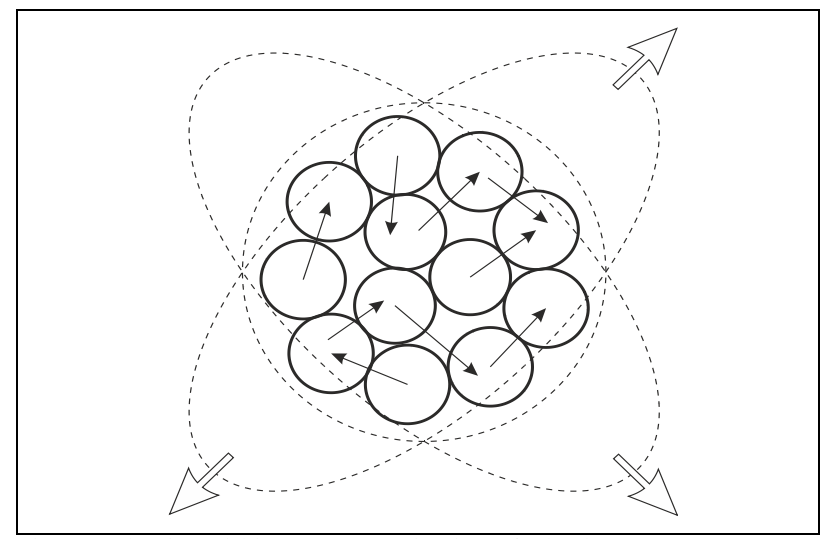

Fig. 3. Behavior within a CD-organization of a business system

By increased speed and different directions for transformation of knowledge, we ensure that knowledge is transferred from an individual level to the level of a business system. A common core of a CD organization assures that the speed of knowledge circulation/exchange, influences also the speed of exchange and transformation of capital in a business system.

CD- organization takes different forms under the pressures from its environment. Its elasticity is based on permanent transformation within its basic business units and their mutual solidarity. Awareness that the risk of functioning of the entire business system can be solved only by another, bigger risk in which they can always rely on their common core of knowledge and capital which was built partially by themselves. Each basic business unit is solidary in admitting negative effects of another business unit, helping in that way to amortize instability, by providing elasticity to the entire system and its balance.

This gives a chance to the endangered unit to stabilize or transform in time. A deformed organization, depicted as elasticity of CD organization is temporary. Power of a $\mathrm{CD}$ organization relies on the strength of basic business units that are mentally sound enough to sustain basic business units up to a certain level of temptation, or in other words, they are sensible enough to start a transformation process in time. In this way influence of the market or competition is increased - eventually giving the importance to the consumer as the star of the entire process. Thus we can point out stimulation of cooperation, partnership and joint ventures as important forms of functioning of basic business units.

The only common goal of a CD organization of business system is success, and all other is left to the imagination of basic business units. Networking, multiplication and combining of modules is an important feature of $\mathrm{CD}$ organization of a business system, which assures that it is much bigger as a whole - much more than just the sum of its parts.. A CD-based organization has solved barriers of time, legislation, geography and culture. By mixing cultures, preferences and experiences, it opens numerous new possibilities for a man- an individual as a basis for a CD organization of a business system

\section{CONCLUSION}

By creating a CD organizational structure, we offer an organizational solution in which through networking we reached horizontal cores without hierarchy. We gained an organization in which offer and exposure to competition is fought by a more dynamic offer. A permanent process of circulation - transformation of knowledge, capital and ownership leads a CD organization of a business system toward a selfgoverning structure.

The process of stimulation of the very holder of business units or their parts is a basis for speeding up of innovativeness and re-creating of new value. By relying on an individual, we go beyond vertical hierarchy barriers. Reducing basic business units and multiplying knowledge, we increase all the characteristics of the entire business system, or even better, the entire business idea.

\section{REFERENCES}

[1] Vizjak, A. (2011). Formule uspjeha za novo desetljeće (Formula of success for a new decade), ISBN 978-953-246-128-2, , Mate , Zagreb

[2] Prester, J. (2010). Menadžment inovacija (management of innovation), ISBN 978-953-6895-40-3, „, Sinergija , Zagreb

[3] Ridderstrale, J. \& Nordstrom, K. (2004). Karaoke kapitalizam (Karaoke capitalisam-management for manking), ISBN 95396545-3X, , Differo „, Zagreb

[4] Kaku, M. (2011). Fizika budućnosti (Pleysics of the future:how scieuse will change -daily life by 2100),ISBN 978-953-246-1343, , Mate , Zagreb 